\title{
A LEGISLAÇÃO VIGENTE PARA A EDUCAÇÃO MUSICAL NAS SÉRIES INICIAIS DO ENSINO FUNDAMENTAL NA REGIÃO CENTRO-OESTE
}

\author{
Prof. Dr. Sérgio Luiz Ferreira de Figueiredo \\ Ramon Franco Sezerino \\ Gabriel Ferrão Moreira
}

\begin{abstract}
Palavras-chave: Legislação educacional- Educação musical - Séries iniciais do ensino fundamental

Resumo: Este texto apresenta aspectos de uma pesquisa em andamento cujo tema é a influência da legislação educacional atual sobre o ensino de música nas séries iniciais do Ensino Fundamental. O modelo qualitativo de pesquisa é utilizado nesta investigação, e nesta primeira fase do projeto os métodos de coleta de dados envolveram pesquisa bibliográfica e pesquisa em websites das secretarias de educação de todos os estados brasileiros e do Distrito Federal. Uma ampla revisão de literatura foi realizada até o presente momento incluindo legislação federal e estadual, assim como, textos de autores que discutem a legislação educacional brasileira. Este texto trata especificamente de aspectos da revisão da literatura e dos dados coletados na região Centro-Oeste. Neste momento a pesquisa está sendo continuada através da busca por atualizações nos websites das referidas secretarias.
\end{abstract}

Keywords: Educational legislation - Music education - Primary education

\begin{abstract}
This text presents some aspects of a going-on research whose theme is the influence of the current educational legislation on the music teaching process in the initial grades of Fundamental Teaching in Brazil - equivalent to Primary education. The qualitative model is used in this investigation and the data collecting methods have encompassed bibliographical research and also consultation of the Educational Department websites of all Brazilian states and Federal District. The review of literature has been done until now, including federal and state legislation, as well as texts from authors who discuss the Brazilian educational legislation. This text presents specifically aspects of the review of literature and the collected data of the Central-Western Brazilian region. By this moment the research has been continuing through the search of updated pieces of information in the websites of the departments cited above.
\end{abstract}




\section{INTRODUÇÃO}

A legislação vigente para a educação nas séries iniciais é o objeto de estudo deste projeto de pesquisa que teve seu início no segundo semestre de 2006 apresentando como objetivo principal o estudo da legislação educacional para compreender como tal legislação tem afetado a educação musical nas séries iniciais do Ensino Fundamental.

A reflexão sobre a situação da educação musical nas séries iniciais é necessária uma vez que buscar apresentar propostas que aprimorem a legislação para a educação musical nas séries iniciais também é um dos objetivos do projeto além de obter dados a respeito da acessibilidade, aplicação, funcionalidade e liberdade de interpretação a respeito da legislação vigente.

O texto apresenta aspectos da metodologia da pesquisa, questões da legislação brasileira discutidas na literatura da área. Esses aspectos metodológicos correspondem à revisão de literatura, assim como resultado da coleta e organização de dados da região centro-oeste especificamente.

\section{CARACTERÍSTICAS DA LEGISLAÇÃO}

Discutir as leis brasileiras é a margem que se dá à interpretação de seus conteúdos. Essa questão torna-se ainda mais grave quando o assunto é arte, conceito bastante relativo. Juntando-se um conceito relativo à legislação - e, ainda mais, à frágil estrutura escolar brasileira, torna-se bastante delicado o tratamento da arte como disciplina do ensino fundamental, ainda que os documentos tragam orientações a esse respeito.

Falar sobre políticas educacionais é, portanto, falar sobre políticas de acordos e alianças; é desvendar o cenário onde nos movemos, o pano político de fundo e os bastidores das discussões. E na área específica de Educação Musical o processo não é diferente. (JUSAMARA, 1998, p.18).

\section{LDBEN 9394/96}


A Lei de Diretrizes e Bases da Educação Nacional - LDBEN - atualmente regulamenta os níveis e modalidades de educação e ensino (educação básica, educação profissional, educação superior, educação especial) estabelecendo normas à educação brasileira. Em relação à educação básica, especificamente ao ensino fundamental, a LDBEN estabelece áreas que devem fazer parte dos currículos nacionais, resguardadas as diferenças regionais.

Art. 26. Os currículos do ensino fundamental e médio devem ter uma base nacional comum, a ser complementada, em cada sistema de ensino e estabelecimento escolar, por uma parte diversificada, exigida pelas características regionais e locais da sociedade, da cultura, da economia e da clientela.

$\S 2^{\circ}$. O ensino da arte constituirá componente curricular obrigatório, nos diversos níveis da educação básica, de forma a promover $o$ desenvolvimento cultural dos alunos. (BRASIL, 1996)

A LDBEN determina que a organização do sistema de educação nacional seja mantida pela União, Estados, Distrito Federal e Municípios. Estabelece também a obrigatoriedade dos educadores apresentarem formação em nível superior, em curso de licenciatura, de graduação plena em universidades e instituições superiores de educação.

\section{PCN}

O objetivo inicial dos Parâmetros Curriculares Nacionais - PCN - é servir de instrumento mediador nas discussões pedagógicas e de base para elaboração de projetos educativos, de planejamentos de aulas e para a análise e reflexão quanto à prática educativa, material didático e assuntos pertinentes à escola.

Sua função é orientar e garantir a coerência dos investimentos no sistema educacional, socializando discussões, pesquisas e recomendações, subsidiando a participação de técnicos e professores brasileiros (BRASIL, 1997a)

Sobre as aulas de arte no ensino fundamental, os PCN indicam uma relação entre aulas e as demais disciplinas da escola, buscando conexão com a cultura local e o espaço 
temporal que contextualizam as aulas. Contudo, sabe-se que os PCN não constituem uma regra a ser estritamente seguida, mas um guia para a prática escolar.

Por sua natureza aberta, configuram uma proposta flexível, a ser concretizada nas decisões regionais e locais sobre currículos e sobre programas de transformação da realidade educacional empreendidos pelas autoridades governamentais, pelas escolas e pelos professores. (BRASIL, 1997a)

Os PCN atendem a música em dois documentos organizados para a área da arte, sendo o primeiro referente à $1^{\mathrm{a}}$ a $4^{\mathrm{a}}$ séries $\left(1^{\mathrm{o}}\right.$ e $2^{\mathrm{o}}$ ciclos do ensino fundamental) e $5^{\mathrm{a}}$ a $8^{\mathrm{a}}$ séries ( $3^{\circ}$ e $4^{\circ}$ ciclos do ensino fundamental).

\section{O QUE OS AUTORES DIZEM SOBRE LDBEN E PCN}

Diversos autores analisaram a legislação mostrando seus aspectos positivos e negativos. Lima (2000) considera a LDBEN como documento que não especifica de quem é o papel da organização curricular para o ensino de arte nas escolas.

A LDB n9394/96 permite ampla liberdade de ação para elaboração dos projetos escolares, preocupando-se mais em criar parâmetros curriculares do que em impor um conteúdo curricular determinado. (LIMA, 2000, p.40).

A realidade das escolas difere daquela proposta pelos documentos norteadores da educação básica. Partindo do pressuposto que o ensino de arte contribui para outras disciplinas do currículo, tratando de forma natural e fazendo conexões com conceitos de cada área de conhecimento, nota-se que isso não é exatamente o resultado esperado.

O documento dos PCN-Arte, que apresenta uma proposta tão abrangente, não chega, na verdade, a encarar de frente a questão de como viabilizar o trabalho com as diversas linguagens artísticas na escola. (PENNA, 1998, p.70).

Quando ocorre essa inserção das aulas de artes nas escolas, muitas vezes uma única área é privilegiada. 
A presença de diferentes linguagens nem sempre acontece na prática e isso merece um exame cuidadoso. O que se encontra, na realidade, é, muitas vezes, a exclusividade da aula de artes plásticas, fazendo com que os alunos não entrem em contato com as outras linguagens artísticas, como a música, a dança e o teatro. (FERNANDES, 2004, p.76)

A música é, segundo os PCN (BRASIL, 1997b), uma das possibilidades das aulas de arte no ensino fundamental, considerada assim porque está associada às tradições e culturas de cada época e região. As aulas de música no ensino fundamental incluem atividades de interpretação de música, o que pode ser julgado como apreciação e execução, inovação e criação.

Atualmente, o desejo de que os profissionais da área de educação estejam a par da legislação educacional existe. A respeito desses documentos, todos "exigem [...] uma análise profunda e amplas discussões, que envolva, entre outros aspectos, questões relativas à política educacional” (PENNA, 1998, p.61).

\section{METODOLOGIA}

Estão sendo estudados documentos oficiais produzidos pelos 26 estados brasileiros e o DF referentes à educação musical nas séries iniciais do ensino fundamental, coletados a partir de websites das respectivas secretarias de educação e também de documentos escritos disponíveis utilizando assim elementos da pesquisa documental.

\section{COLETA DE DADOS}

Nesta pesquisa, de caráter qualitativo, foi realizada a coleta de documentos referentes à legislação educacional em locais de acesso público. Segundo Gil (1999), a técnica de utilizar documentos oficiais permite obter uma grande variedade de dados para investigação sem precisar envolver a participação direta de pessoas.

Os dados coletados através da pesquisa documental referem-se às Leis, Decretos, Portarias, Ementas, Parâmetros, e outros documentos que tratam do ensino de música nas séries iniciais do Ensino Fundamental nos estados brasileiros e no Distrito Federal. 


\section{INTERNET}

A internet foi a fonte inicial de documentos na primeira etapa. Para a realização da coleta de documentos, definiu-se uma rotina - 'filtros' - que foi seguida pelos integrantes no momento da verificação dos websites. Esses filtros foram elaborados seguindo as seguintes etapas:

$1^{\text {a }}$ - verificação das secretarias de educação de cada estado (por região);

$2^{a}$ - verificação da legislação do ensino fundamental;

$3^{\mathrm{a}}$ - verificação dos documentos para as séries iniciais;

$4^{\mathrm{a}}$ - verificação da incidência das palavras "arte" e "música" nos documentos;

$5^{\mathrm{a}}$ - verificação de outros níveis de ensino; e

$6^{\mathrm{a}}$ - verificação da existência de projetos envolvendo música.

\section{FILTROS DE PESQUISA E ORGANIZAÇÃO}

Tabelas foram elaboradas a fim de catalogar os documentos encontrados nos websites em cada verificação realizada. As coletas obedeceram a um período específico de tempo entre setembro, outubro, novembro de 2006 e março, abril e junho de 2007. O objetivo desta periodicidade era conferir as informações contidas em cada website e verificar possíveis alterações.

As Tabelas 1 e 2 exemplificam o registro dos dados coletados através dos 'filtros' em diferentes períodos.

Tabela 1 - Documentos coletados na Secretaria de Educação do estado do Rio de Janeiro em 09/2006.

\begin{tabular}{|c|c|c|}
\hline $\begin{array}{c}\text { Estado } \\
\text { Pesquisado }\end{array}$ & $\begin{array}{c}\text { Data de } \\
\text { Verificação }\end{array}$ & $\begin{array}{c}\text { Documentos Encontrados Sobre A Legislação Das Séries Iniciais } \\
\text { Do Ensino Fundamental e Documentos Complementares }\end{array}$ \\
\hline $\begin{array}{l}\text { Rio de } \\
\text { Janeiro }\end{array}$ & $\begin{array}{l}\text { Setembro } \\
\text { de } 2006\end{array}$ & $\begin{array}{l}\text { 1- Deliberação } \mathbf{N}^{\circ} \mathbf{2 6 5 - 0 1}-\mathbf{R J} \text { (trata sobre a formação de } \\
\text { professores em curso de ensino médio na modalidade normal para a } \\
\text { educação infantil e para os quatro primeiros anos do ensino } \\
\text { fundamental, cita artes) pág.02 } \\
\text { 2- Resolução CEB-CNE } \mathbf{N}^{\circ} \mathbf{0 2 - 9 9}-\mathbf{R J} \text { (trata sobre a inserção de } \\
\text { Diretrizes Curriculares Nacionais para a formação de docentes da } \\
\text { educação infantil e dos anos iniciais do ensino fundamental, em nível } \\
\text { médio, na modalidade normal.) pág. 02 }\end{array}$ \\
\hline
\end{tabular}

DAPesquisa, Florianópolis, v.2, n.4, p. 535-546, 2007. 
Tabela 2 - Documentos coletados na Secretaria de Educação do estado do Rio de Janeiro em 10/2006.

\begin{tabular}{|c|c|c|}
\hline $\begin{array}{c}\text { Estado } \\
\text { Pesquisado }\end{array}$ & $\begin{array}{c}\text { Data de } \\
\text { Verificação }\end{array}$ & $\begin{array}{c}\text { Documentos Encontrados Sobre A Legislação Das Séries Iniciais } \\
\text { Do Ensino Fundamental e Documentos Complementares }\end{array}$ \\
\hline $\begin{array}{l}\text { Rio de } \\
\text { Janeiro }\end{array}$ & $\begin{array}{l}\text { Outubro } \\
\text { de } 2006\end{array}$ & $\begin{array}{l}\text { Além dos documentos encontrados anteriormente: } \\
\text { 1- Resolução } \mathbf{N}^{\circ} \mathbf{2 6 4 0 - 0 4}-\mathbf{R J} \text { (trata sobre as matrizes curriculares } \\
\text { da educaçáo básica nas unidades escolares da rede pública estadual, } \\
\text { trata das artes no ensino infantil e ensino fundamental) pág. } 03 \\
\text { Documentos Complementares: } \\
\text { 1- Práticas Pedagógicas - } \mathbf{R J} \text { (trata sobre a importância e como deve } \\
\text { ser realizada a prática pedagógica) }\end{array}$ \\
\hline
\end{tabular}

Nos documentos coletados foram selecionados trechos referentes às artes ou à música nas séries iniciais do ensino fundamental. Os documentos foram catalogados e serão analisados futuramente.

\section{REGIÃO CENTRO-OESTE}

Serão apresentados brevemente aspectos encontrados no levantamento de documentos dos estados de Goiás, Mato Grosso e Mato Grosso do Sul, e Distrito Federal.

No DF foi encontrado o documento intitulado "Currículo da educação básica das escolas públicas do Distrito Federal - Ensino Fundamental - $1^{\mathrm{a}}$ a $4^{\mathrm{a}}$ série" do ano de 2002 responsável pela aplicação de normas curriculares de ensino.

Neste documento, primeiramente, o conceito de arte é apresentado como uma atividade cuja forma completa a essência do ser humano e como algo fundamental para sua formação:

o aluno percebe a interação de seu próprio corpo, suas mãos e seus olhos adquirem habilidades, o ouvido e a palavra se aprimoram, enquanto desenvolve atividades nas quais relações interpessoais perpassam o convívio social o tempo todo. (DF, 2002, p.24)

No ensino fundamental, o documento mostra conteúdos relacionados às quatro séries iniciais envolvendo habilidades, procedimentos e práticas pedagógicas. Afirma-se 
que todas as habilidades devem ser trabalhadas juntas a fim de garantir o exercício de 3 princípios norteadores.

... foram eleitos três eixos, que devem nortear o ensino de Arte, nas quatro séries iniciais do Ensino Fundamental: Representação e Comunicação, Investigação e Compreensão, e Contextualização Sociocultural. Apesar de serem distintos, os eixos devem ser trabalhados em conjunto (DF, 2002, p.31)

Apresentando questões definidas a respeito do ensino de arte e de música no ensino fundamental, este, estabelece orientações a serem trabalhadas e a liberdade de desenvolvimento de cada uma delas. Entretanto, falando de contribuições à prática pedagógica, no currículo de ensino, a música e a dança não são consideradas conteúdos obrigatórios às séries iniciais, porém, apresentam importância na sua formação.

Trabalhar as linguagens Dança e Música em projetos, sem reduzí-los a mera alegoria ou descontração. Mesmo sendo Arte Visual [...] essas duas linguagens oferecem valiosa contribuição à aquisição de habilidades significativas para a formação do aluno-cidadão, desde que inseridas numa proposta de ensino sistematizado e não como pano de fundo de outras atividades, ditas mais importantes. (DF, 2002, p.121-122)

Tanto MT quanto MS possuem um "Plano Estadual de Educação" que visa atender as metas dos estados em relação ao atendimento escolar em todos os níveis de ensino.

Em ambos, os documentos são recentes e oferecem conteúdo referente a todas as áreas de ensino, desde a educação infantil até a superior abrangendo também a formação de profissionais. Os dois estados visam a participação da sociedade na formulação e cobrança da aplicação dos planos:

no Plano Estadual de Educação para Mato Grosso estão definidas as dimensões do modelo de educação a ser construído, através do diálogo e do controle da sociedade. (MT, 2006, p. 8)

Compete a cada cidadão sul-mato-grossense acompanhar a aplicação deste Plano Estadual de Educação para que os ideais que nortearam a sua elaboração configurem-se em mecanismos de compromisso para a criação de um novo cenário educacional para o nosso Estado. (MS, 2004, p.4)

DAPesquisa, Florianópolis, v.2, n.4, p. 535-546, 2007. 
Em nenhum dos dois estados - MT e MS - os planos tratam do ensino de arte. Mas em MS outro documento intitulado "Lei do Sistema Estadual de Ensino" refere-se a organização do sistema estadual de ensino, informando a respeito do ensino de artes e sua obrigatoriedade na educação básica.

$\S 1^{\circ} \mathrm{O}$ ensino de Artes constituir-se-á disciplina obrigatória na matriz curricular das diversas etapas da educação básica, integrando pessoas do mundo das artes, grupos e movimentos culturais locais, tendo como finalidade promover os diferentes valores culturais dos alunos. (MS, 2004, p.21)

Em GO não foi encontrado um plano estadual de educação assim como um guia curricular para a educação, mas sim um documento semelhante àquele encontrado no estado de MS. Esse documento, intitulado "Lei Complementar n²6”, é do ano de 1998 e refere-se à organização do sistema estadual de ensino.

Relacionado à educação básica, o ensino de arte aparece como obrigatório em todos os níveis:

$\S 3^{\circ}$ - O ensino de arte constitui componente curricular obrigatório, nos diversos níveis da educação básica, de forma a promover $o$ desenvolvimento criativo, cultural e estético dos alunos:

a) entende-se por ensino de arte os componentes curriculares pertinentes às artes musicais, plásticas, cênicas, e demais formas de manifestação artística. (GO, 1998, p. 13)

Após verificação, pode-se considerar que há falta de clareza em relação ao que está escrito assim como há falta de documentos norteadores para a aplicação do ensino de artes, especificamente para a área de música.

\section{CONSIDERAÇÕES FINAIS}

Em primeiro momento, realizou-se uma revisão de literatura que até o fim da pesquisa será ampliada. Paralelamente à essa revisão de literatura , realizou-se a coleta de dados nos websites de todas as secretarias de educação dos 26 estados brasileiros e Distrito Federal. 
As principais dificuldades encontradas referem-se à falta de atualização dos dados dos websites, causadas por diversos fatores que não entram em questão neste momento, mas faz-se necessário relatar alguns problemas que surgiram no decorrer da coleta:

$1^{\circ}$ - a falta de materiais disponíveis nos websites das secretarias de educação;

$2^{\circ}$ - falta de atualização dos dados por parte dos responsáveis pelos websites; $3^{\circ}$ - a mudança de secretários de educação dos 26 estados brasileiros e do Distrito Federal; e $4^{\circ}$ - a impossibilidade e a falha em acessar alguns websites não disponíveis na rede.

Por não serem tão acessíveis como pensado, acredita-se que muitos profissionais da área da educação musical ou até mesmo outras áreas não se interessem pelos documentos.

Partindo da coleta nos websites, a nova etapa é marcada pelo pedido desses documentos a todas as secretarias de educação do país via correspondência. Assim se pretende aumentar o acervo de documentos que servirão para a fase analítica da pesquisa. Todas as cartas de pedido de documentos foram enviadas em maio de 2007. Nestes ofícios foi solicitado que as secretarias disponibilizem documentos oficiais para a realização da pesquisa.

Por fim, será realizada a análise de todo o material coletado entre documentos federais, estaduais e municipais, permitindo conhecer mais detalhadamente de que forma tal legislação tem afetado a educação musical na escola.

\section{REFERÊNCIAS BIBLIOGRÁFICAS}

BRASIL. Lei de Diretrizes e Bases da Educação Nacional, LDB: Lei 9394/96. Brasília:

Diário Oficial da União, Ano CXXXIV, n. 248, de 23/12/96, pp. 27.833-27.841, 1996.

BRASIL. Introdução aos parâmetros curriculares nacionais. Brasília: MEC: Secretaria de Educação Fundamental, 1997a. 
BRASIL. Parâmetros curriculares nacionais: Arte. Brasília: MEC: Secretaria de Educação Fundamental, 1997b.

DISTRITO FEDERAL (Brasil). Secretaria de Estado de Educação. Currículo da educação básica das escolas públicas do Distrito Federal: ensino fundamental $1^{\mathrm{a}}$ a $4^{\mathrm{a}}$ série. $2^{\mathrm{a}}$ Edição, Secretaria de Estado de Educação. - Brasília: Subsecretaria de Educação Pública, 2002.

FERNANDES, José Nunes. Normatização, estrutura e organização do ensino da música nas escolas de educação básica do Brasil: LDBEN/96, PCN e currículos oficiais em questão. Revista da ABEM, Porto Alegre, RS, V.10, p.75-87, mar.2004.

GIL, Antônio Carlos. Métodos e técnicas de pesquisa social. $5^{\text {a }}$ ed., Atlas, São Paulo, SP, 1999.

GOVERNO DO ESTADO DE GOIÁS. Lei Complementar n²6 - V ide Decreto nº4.368 / 1994. Gabinete Civil da Governadoria. Superintendência de Legislação. Dez de 1998.

GOVERNO DO ESTADO DE MATO GROSSO. Fórum Estadual de Educação. Plano Estadual de Educação de Mato Grosso. Cuiabá, MS, 2006.

GOVERNO DO ESTADO DE MATO GROSSO DO SUL. Secretaria de Estado de Educação. Lei do Sistema Estadual de Ensino de Mato Grosso do Sul. Campo Grande, MS, 2004.

GOVERNO DO ESTADO DE MATO GROSSO DO SUL. Secretaria de Estado de Educação. Plano Estadual de Educação de Mato Grosso do Sul. Campo Grande, MS, 2005.

JUSAMARA, Souza. Parâmetros curriculares nacionais: Ensino fundamental e médio, políticas e ações para o ensino de música nas escolas. VII Encontro Anual da Associação Brasileira de Educação Musical, Recife, PE, p.17-26, 1998. 
LIMA, Sonia Albano. A educação profissional de música frente à LDB nº.393/96. Revista da ABEM, Porto Alegre, RS, V.05, p.39-43, set.2000.

PENNA, Maura. Discutindo o ensino de música nas escolas: os PCN para os $3^{\circ}$ e $4^{\circ}$ ciclos e sua viabilidade. VII Encontro Anual da Associação Brasileira de Educação Musical. Recife, ABEM, 1998.

DAPesquisa, Florianópolis, v.2, n.4, p. 535-546, 2007. 